\title{
32 THE TRIPLE HELIX, OPEN INNOVATION, AND THE DOI RESEARCH AGENDA
}

\author{
Gabriel J. Costello \\ Galway-Mayo Institute of Technology and \\ National University of Ireland \\ Galway, Ireland \\ Brian Donnellan \\ National University of Ireland \\ Galway, Ireland \\ Ivor Gleeson \\ Central Applications Office \\ Ireland \\ Colm Rochford \\ American Power Conversion \\ Castlebar, Ireland
}

\begin{abstract}
This paper examines the implications for research on the diffusion of innovations (DOI) arising from a growing body of literature in two related fields. The first area concerns the debate on the role of regional and national systems of innovation in the innovation process. The second area deals with the argument that enterprises must move from a "closed innovation" to an "open innovation" paradigm. The review is presented in the context of a case study being undertaken in a subsidiary of American Power Conversion (APC) located in the West of Ireland. Based on the preliminary stages of our work, we present a conceptual 3-D model of Rogers 'innovation-decision process and suggest a series of propositions to stimulate future research efforts.
\end{abstract}

Please use the following format when citing this chapter.

Costello, G. J., Donneilan, B., Gleeson, I., and Rochford, C., 2007, in IFIP International Federation for Information Processing, Volume 235, Organizational Dynamics of Technology-Based Innovation: Diversifying the Research Agenda, eds. McMaster, T., Wastell, D., Ferneley, E., and DeGross, J. (Boston: Springer), pp. 463468 . 


\section{INTRODUCTION}

Over the last decade, significant literature has emerged in two areas related to innovation, first with the debate on the role and composition of national systems of innovation and second with the argument that enterprises must move from a closed innovation to an open innovation paradigm. The aim of this paper is to examine the consequences of this literature for research on the diffusion of innovations (DOI) and in particular on Rogers' (2003) work on the innovation-development process. The paper is presented in the context of a case study in a subsidiary of American Power Conversion (APC) located in Ireland's Border, Midland, and Western (BMW) region. The paper proceeds as follows. First, the research context is outlined in terms of the evolving Irish economy and the regional situation. A brief literature review is then presented of enterprise innovation models and of national systems of innovation. The next section provides an overview of an ongoing longitudinal case study on innovation being carried out in APC. Following this, a perspective is presented that realigns Rogers' two-dimensional innovation process to a more externally focused three-dimensional model. Finally, based on the context and literature, we propose a revised DOI research agenda together with suggestions for future work.

\section{BACKGROUND}

Over the last 40 years, Ireland has leapfrogged from a traditional agrarian economy to a deliberately created information economy (Trauth 2000). The initial impetus was fueled by foreign direct investment from North American multinational corporations setting up offshore manufacturing facilities to avail of tax incentives; a young, educated workforce; and proximity to their growing number of European customers. However, this initially successful model is increasingly being threatened by the low cost economies of Eastern Europe, India, and China. Irish enterprises rapidly need to build new sources of competitive advantage to sustain employment and standards of living. The Border, Midland, and Western (BMW) region of Ireland is designated by the European Union as "Objective 1": a less well developed area that qualifies for additional structural funds under the European Union state aid scheme. It is also one of the fastest growing regions of Europe but needs to increase absorptive capacity. Ireland is now entering a new era which, according to Porter (2003), requires a transition to an innovation economy

\section{CHANGING INNOVATION PARADIGMS}

The innovation-development process as defined by Rogers (2003,p. 138) consists of the six steps shown in Figure 1. The methodology includes all the decisions, activities, and their impact from the initial recognition of a need, followed by research, development, and commercialization through to diffusion and evaluation of the consequences.

Chesbrough (2003) argues that, in many industries, the centralized approach to R\&D described above, which he terms closed innovation has become obsolete. This paradigm, he contents, must be replaced by open innovation, which adopts external ideas and knowl- 


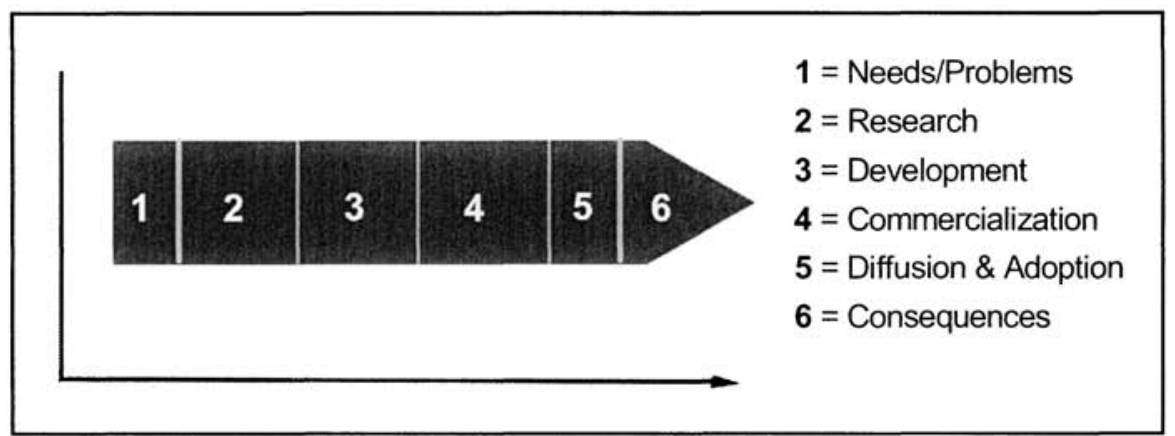

Figure 1. The Innovation-Decision Process (adapted from Rogers 2003, p. 138)

edge in conjunction with the internal process. A number of factors are influencing this change such as the mobility of skilled people, the increasing presence of venture capital, emergent high-tech start-ups, and the significant role of university research. The increasingly important role of academia in supporting innovation in knowledge-based societies has led to the development of a number of models from national systems of innovation (Lundvall 1995) to the more recent triple helix model of university-industrygovernment relations (Etzkowitz and Leydesdorf 2000). The latter is illustrated in Figure 2, which has been adapted to emphasize the focal area of interaction, highlighted in the Venn diagram.

However, while the reality of the growing association between academia and enterprises is widely accepted, the nature of the involvement is still a matter of lively debate (Manimala 1997, p. 111).

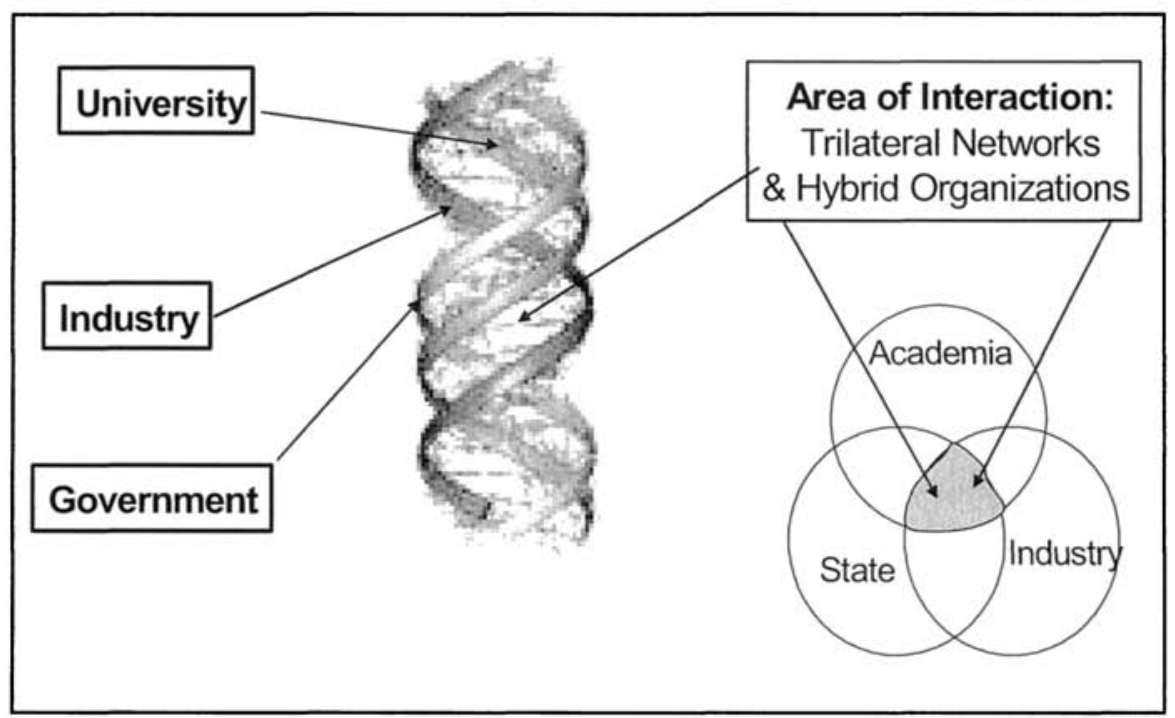

Figure 2. The Triple Helix (adapted from Etzkowitz and Leydesdorf 2000) 


\section{CASE STUDY}

The case study is based in APC Ireland, a subsidiary of the American Power Conversion (APC) Corporation. APC designs, manufactures, and markets back-up products and services that protect hardware and data from power disturbances. The explosive growth of the Internet has resulted in the company broadening its product offerings from uninterruptible power supplies to the high-end InfraStruXure ${ }^{\mathrm{TM}}$ architecture in order to meet the critical availability requirements of Internet service providers and data centers. This phenomenon has resulted in a value chain realignment from selling products or services to providing integrated customer solutions, typical of many information and communication technology corporations in knowledge-based economies (Grimes 2003). APC entered a major period of transition in the second-half of 2006 with the announcement of its merger with Schneider Electric.

\section{IMPLICATIONS FOR THE DOI RESEARCH AGENDA}

Figure 3 illustrates the conceptual model of a 3-D innovation process that realigns the 2D model of Figure 1 to include the dynamics of the triple helix. Using this perspective, we contend that organizations with closed innovation processes need to accommodate the dimensions of open innovation and engage with other significant regional actors.

Having illustrated our argument that Rogers diffusion theory needs to be updated based on the current debates on the concepts and structures of national systems of innovation and open innovation models, we will now discuss the implications for research.

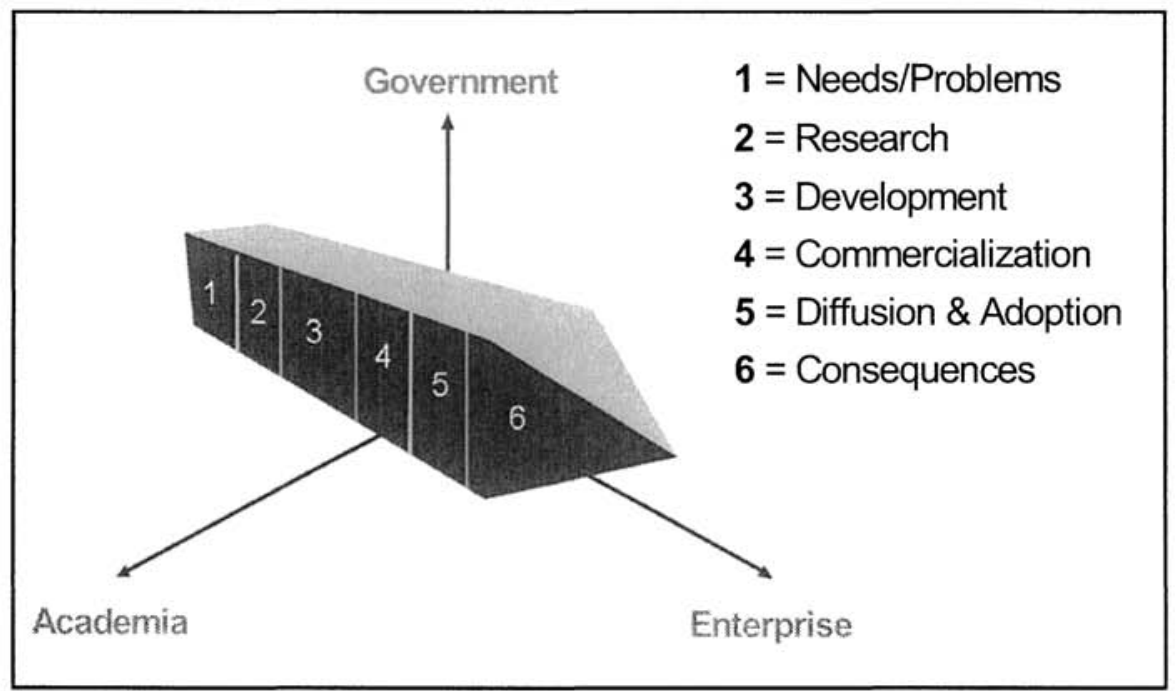

Figure 3. 3-D Representation of Rogers' Innovation-Decision Process 


\subsection{Issues for the Research Agenda}

A research agenda provides the impetus for planning and developing more detailed studies of a particular area. Arising from our previous discussion, we now propose the examination of the following issues that could contribute to refreshing the DOI research agenda:

1. Issues associated with regional innovation.

2. Issues associated with the innovation process within open organizations.

3. Issues associated with developing more integrated and interactive collaboration between a region and its organizations.

4. Issues associated with management of the innovation process in a 3-D reference frame.

\subsection{Suggestions for Future Work}

Arising from the issues presented above, we suggest a number of topics to stimulate future work.

1. Developing a triple helix model of, for example, the BMW region, showing the main actors, roles, and areas of interaction.

2. Examining the phases and deliverables of current closed innovation methodologies in the light of the open innovation paradigm.

3. Identifying the main areas of interaction between the regional model and the organizational innovation process with a view to more productive collaboration. We also raise the question whether each of Rogers' six steps needs its own triple helix.

4. Exploring the implications for innovation project and portfolio management arising from the 3-D perspective. Associated with this, we suggest investigating the consequences of moving from product and service innovation to "solutions" innovation.

\section{CONCLUSIONS}

This paper has provided a review of Rogers' innovation-development process in the light of a movement to open innovation within the triple helix of academia-enterprisegovernment. Following a review of the literature and the regional context, a conceptual model of a 3-D innovation process that realigns the current 2-D model to include the dynamics of the triple helix was illustrated. The paper argued that Rogers' innovation process needs to be updated to take into account these paradigms. Future work was suggested for a more detailed investigation of the implications of this perspective on the integration of regional and organizational innovation structures and methodologies.

\section{References}

Chesbrough, H. W. Open Innovation: The New Imperative for Creating and Profiting from Technology, Boston: Harvard Business School, 2003. 
Etzkowitz, H., and Leydesdorf, L. "The Dynamics of Innovation: From National Systems and 'Mode 2' to a Triple Helix of University-Industry-Government Relations," Research Policy (29), 2000, pp. 109-123.

Grimes, S. "Ireland's Emerging Information Economy: Recent Trends and Future Prospects," Regional Studies (37:1), 2003,pp. 3-14.

Lundvall, B.-A. National Systems of Innovation: Towards a Theory of Innovation and Interactive Learning, London: Pinter, 1995.

Manimala, M. J. "Higher-Education-Enterprise Co-operation and the Entrepreneurial Graduate: The Need for a New Paradigm," in J. Mitra and P. Formica (eds.), Innovation and Economic Development: University-Enterprise Partnerships in Action, Dublin: Oak Tree, 1997.

Porter, M. "Irish Competitiveness: Entering a New Economic Era," IMI Top Management Briefing, Dublin, Ireland, October 9, 2003 (available online at http://www.isc.hbs.edu/pdf/ CAON_Ireland 2003.10.09_CK.pdf).

Rogers, E. M. Diffusion of Innovations $\left(5^{\text {th }}\right.$ ed.), New York: Free Press, 2003.

Trauth, E. M. The Culture of an Information Economy: Influences and Impacts in the Republic of Ireland, Boston: Kluwer Academic Publishers, 2000.

\section{About the Authors}

Gabriel J. Costello is a lecturer at the Galway-Mayo Institute of Technology. Presently, he is also a researcher at the Centre for Innovation and Structural Change (CISC), National University of Ireland, Galway, and is undertaking a Ph.D. in MIS. Prior to this he worked for 20 years in the telecommunications industry. He can be reached by e-mail at gabrielj.costello@gmit.ie.

Brian Donnellan is a lecturer in Information Systems at NUI Galway. His research interests lie primarily in the area of knowledge management systems, which encompasses the use of information systems to support knowledge management, innovation, new product development, and technology management. Prior to this he worked for 20 years in the electronics industry. He can be reached by e-mail at brian.donnellan@nuigalway.ie.

Ivor Gleeson is the general manager and chief executive of ficer of Ireland's higher education Central Applications Office (CAO). Presently, he is undertaking a Ph.D. in Economic and Strategic Management Considerations in the Provision of Computer Software at the National University of Ireland, Galway. He has over 30 years experience in computer programming analysis and design. He can be reached by e-mail at ivor@cao.ie.

Colm Rochford is the plant manager for APC Castlebar. His areas of interest include developing cultures that promote innovative thinking and lean transformation. Prior to this, he held lean transformation and product support roles in APC. He previously worked as a design engineer in the power electronics industry. He can be reached by e-mail at colm.rochford@ apcc.com. 